Lea El Hage, MD

Staff, Endocrinology and Metabolism Institute,

Cleveland Clinic; Clinical Assistant Professor,

Cleveland Clinic Lerner College of Medicine of

Case Western Reserve University, Cleveland, $\mathrm{OH}$
Betul Hatipoglu, MD

Professor of Medicine, CWRU School of Medicine;

Vice Chair, UH System Clinical Affairs, Department

of Medicine; Medical Director, Diabetes \& Obesity

Center; Mary B. Lee Chair in Adult Endocrinology,

University Hospitals Cleveland Medical Center,

Cleveland, $\mathrm{OH}$

\title{
Elevated hCG can be a benign finding in perimenopausal and postmenopausal women
}

\section{ABSTRACT}

In a perimenopausal or postmenopausal woman, an elevation in human chorionic gonadotropin (hCG) can raise the concern of malignancy or even pregnancy, but it can also be a benign physiologic finding due to production in the pituitary gland in this patient population. Diagnosing the underlying cause of hCG elevation can be challenging, especially if a pituitary source is not considered. Pituitary hCG production remains largely underrecognized and can lead to unnecessary testing, harmful therapy such as chemotherapy, or delay in receiving appropriate care for other unrelated diseases. It is therefore important to establish guidelines to aid medical evaluation.

\section{KEY POINTS}

We do not recommend further evaluation in perimenopausal or postmenopausal women when hCG levels are less than $14 \mathrm{IU} / \mathrm{L}$ and follicle-stimulating hormone (FSH) levels are $40 \mathrm{IU} / \mathrm{L}$ or higher.

In patients with hCG levels of $14 \mathrm{IU} / \mathrm{L}$ or higher and FSH levels lower than $40 \mathrm{IU} / \mathrm{L}$, we recommend following the USA hCG Reference Service protocol, which starts with confirming the high hCG level using multiple other assays.
The HUMAN CHORIONIC GONADOTROPIN (HCG) LEVEL is routinely measured to diagnose and monitor pregnancy. In addition, because hCG can be elevated in females with trophoblastic disease, germ cell tumors, and other malignancies, it is often used as a prognostic marker and for disease monitoring. ${ }^{1}$ These days, more women, even those in perimenopause and menopause, are having their hCG levels measured to rule out pregnancy before they undergo imaging studies or treatments that could harm a fetus.

However, elevated hCG levels have been detected in as many as $0.2 \%$ to $10.6 \%$ of perimenopausal and postmenopausal women who are not pregnant and have no disease or tumor. $^{2-4}$ This phenomenon remains underrecognized, and appropriate patient care may be delayed while the source of the elevation is being sought.

In this paper, we review the evidence regarding how to assess perimenopausal and postmenopausal hCG elevation.

\section{STRUCTURE AND BIOLOGY OF hCG}

The heterodimeric glycoprotein hCG is composed of an alpha subunit and a beta subunit. Its alpha subunit is identical to the alpha subunits of luteinizing hormone (LH), follicle-stimulating hormone (FSH), and thyroid-stimulating hormone. The beta subunit, on the other hand, differs among these hormones and determines the hormone's specificity and function. ${ }^{1}$

Fifteen variants of hCG have been detected, ${ }^{5}$ some of which are biologically active, while others are breakdown products and are inactive. The 


\section{TABLE 1}

\section{Common detectable variants of human chorionic gonadotropin (hCG)}

$\begin{array}{ll}\begin{array}{ll}\text { Variant } \\ \text { Intact hCG }\end{array} & \begin{array}{l}\text { Biological } \\ \text { Nicked hCG }\end{array} \\ & \begin{array}{l}\text { Active } \\ \text { Inactive }\end{array} \\ \text { Nicked free beta subunit } & \text { Inactive } \\ \text { Free alpha subunit } & \text { Inactive } \\ \text { Free beta subunit } & \text { Inactive } \\ \text { B-core fragment } & \text { Inactive } \\ \text { Hyperglycosylated hCG } & \text { Active }\end{array}$

\section{Structure}

Attached alpha and beta subunit

Beta-subunit bond broken

Quickly splits into separate alpha and nicked beta subunits

Degraded product of nicked hCG

Final breakdown product of hCG

Similar to intact hCG, with more carbohydrate side chains attached

Based on information in reference 6.

\section{A finding of elevated hCG can lead to confusion and delay in therapy}

most common variants are listed in Table $1 .^{6}$

The variant can suggest the source of the hCG elevation. In normal pregnancy, intact hCG is the predominant form, whereas in trophoblastic disease or testicular tumors, the free beta subunit or hyperglycosylated hCG predominates. ${ }^{7,8}$ More than 100 immunoassay test kits are available to measure hCG. ${ }^{9}$ All kits measure intact hCG along with one additional variant, and it is important to be aware of which hCG variant is being measured in the immunoassay used, especially when evaluating for trophoblastic disease.

Measurement of hCG is usually done using a 2-site noncompetitive immunoassay in which the analyte (hCG) is sandwiched between two antibodies. Certain factors can interfere with the assay and lead to erroneous results. False-positive results can occur from cross-reactivity with other serum glycoproteins or from heterophilic antibodies that can bind to the antibodies used in the hCG assay. ${ }^{10,11}$ False-negative results can occur in cases in which the true hCG level is so high that the assay antibodies become supersaturated. This is known as the "hook effect" and can be avoided through serial dilutions.

\section{ELEVATED hCG IN PERIMENOPAUSAL AND POSTMENOPAUSAL WOMEN}

The exact role of hCG outside of pregnancy remains unclear. In premenopausal women,
hCG and LH levels rise during ovulation. ${ }^{2}$ As women get older, hCG levels, like those of $\mathrm{FSH}$ and $\mathrm{LH}$, rise due to loss of negative feedback inhibition from estrogen and progesterone. ${ }^{2-4,12-16}$ Levels of $\mathrm{hCG}$ and $\mathrm{FSH}$ reach a peak between the ages of 45 and 55 and remain at a plateau thereafter. ${ }^{14}$ In pregnant women, hCG levels have a diurnal variation, rising in the day and decreasing at night. ${ }^{17}$

Confusion can arise when hCG values are higher than the normal laboratory cutoff of 5 IU/L in nonpregnant perimenopausal and postmenopausal women. The prevalence of hCG levels of $5 \mathrm{IU} / \mathrm{L}$ or higher in women between the ages of 41 and 55 is $0.2 \%$ to $0.3 \%$, while in older women it is $8 \%$ to $10.6 \% .^{14,15}$ When hCG is "elevated," physicians often pursue an evaluation for gynecologic disease, malignancy, or paraneoplastic syndrome. Often overlooked, however, is the possibility that the hCG is coming from the pituitary gland.

\section{THE ROLE OF PITUITARY PRODUCTION OF hCG}

Pituitary hCG production was first described in the 1970s after hCG staining was seen in pituitary gland extracts. ${ }^{16,18,19}$ The pituitary gland was also confirmed as a source of hCG production by Stenman et al, ${ }^{16}$ whose work in 1987 showed that hCG levels rose 2- to 3-fold in healthy nonpregnant women and men who were given gonadotropin-releasing hormone 


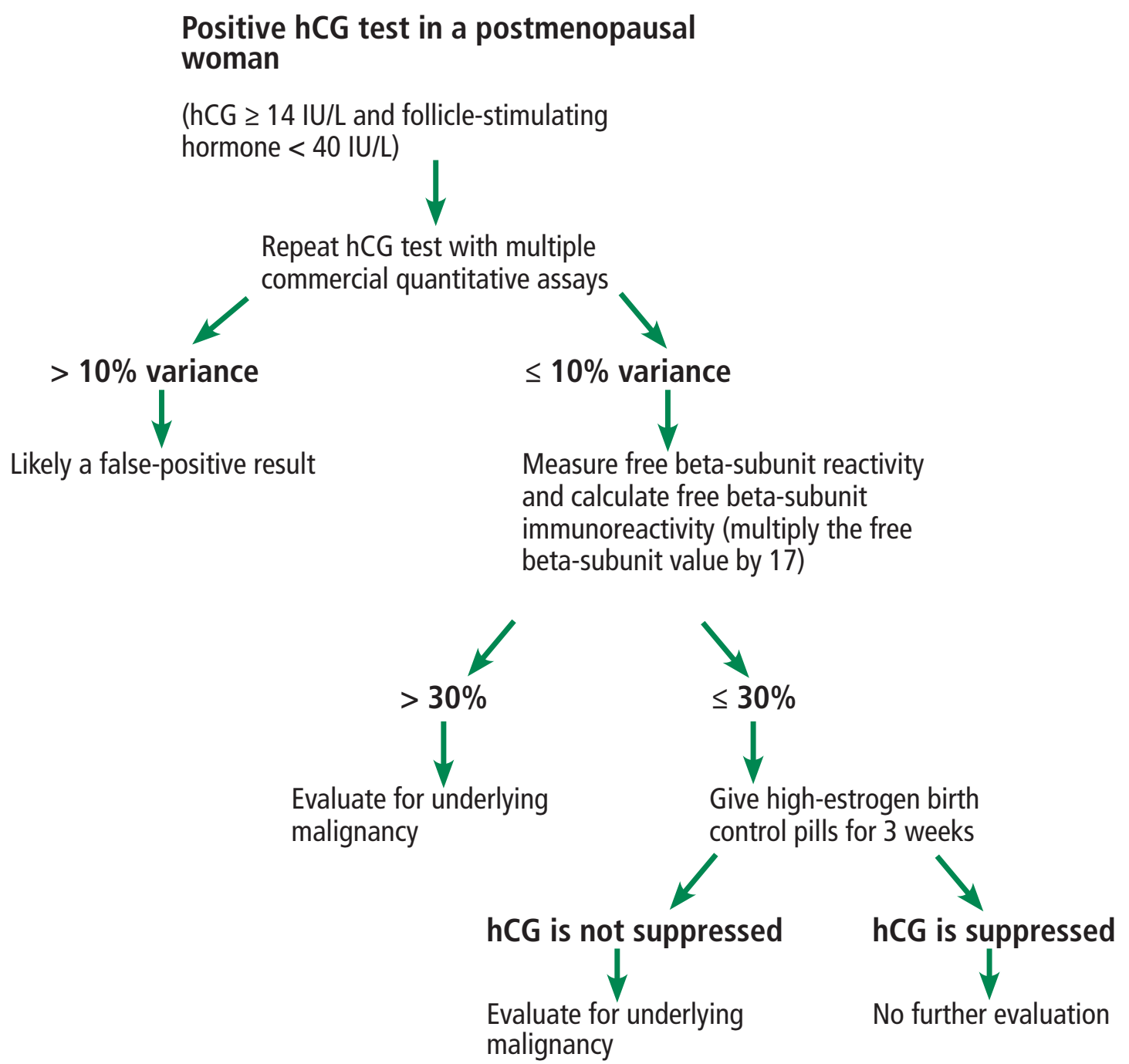

Figure 1. Recommended protocol for evaluating elevated human chorionic gonadotropin (hCG) in postmenopausal women.

Based on information in reference 2 and the authors' recommendations.

$(\mathrm{GnRH})$, and fell in postmenopausal women who were given combined estrogen and progesterone. (In this study, estradiol valerate 2 $\mathrm{mg}$ with medroxyprogesterone acetate $10 \mathrm{mg}$ daily). ${ }^{16}$

Several studies have since investigated this physiologic phenomenon in an attempt to establish hCG cutoff values to help differentiate between a normal physiologic rise in $\mathrm{hCG}$ and a rise related to an underlying pathologic disease. ${ }^{2-4,17,19-21}$ In postmenopausal women, an hCG value of $14 \mathrm{IU} / \mathrm{L}$ has been established as the normal upper limit, while in perimeno- pausal women no clear cutoff value has yet been defined. This is important, as most laboratories give only the reference range for premenopausal nonpregnant women and not the reference range for postmenopausal women.

The FSH level can help distinguish the source of the excess hCG in perimenopausal women, ie, the pituitary vs the placenta (in pregnancy). FSH levels higher than $45 \mathrm{IU} / \mathrm{L}$ were found to have a $100 \%$ negative predictive value for a pituitary origin of elevated hCG. ${ }^{14} \mathrm{FSH}$ levels were not found to correlate with hCG levels in postmenopausal women. ${ }^{15}$ 
Physiologic hCG elevations in perimenopausal and postmenopausal women are still largely unrecognized, and the confusion can delay medical therapy and even lead to unnecessary treatment. Cole et $\mathrm{al}^{3}$ described 28 cases of elevated hCG levels in which unnecessary chemotherapy was given, inappropriate surgery was done, or therapy for other medical conditions was delayed pending workup. The mean hCG level was $9.5 \mathrm{IU} / \mathrm{L}$ (range 2.1-32 IU/L), and the median was $7.7 \mathrm{IU} / \mathrm{L}$. In 18 of these cases, a pituitary source was confirmed by hCG suppression after 2 weeks of hormone therapy.

In another study, ${ }^{2} 18$ of 36 perimenopausal and postmenopausal women with elevated $\mathrm{hCG}$ either received inappropriate medical therapy or experienced delay in surgery. The average hCG level in the perimenopausal women was $6.4 \mathrm{IU} / \mathrm{L}$, and in the postmenopausal women it was $11.6 \mathrm{IU} / \mathrm{L}$. In this series, 24 patients were given high-estrogen birth control pills, which suppressed hCG production in 23 , confirming a pituitary origin. In contrast, hCG levels originating from germ cell tumors are generally significantly higher, as shown in a study by Arrieta et al in which the mean hCG level was $14,772 \mathrm{IU} / \mathrm{L} .^{22}$

After
menopause,
the normal
upper limit
of hCG is 14 IU/L

\section{A PROTOCOL FOR EVALUATING ELEVAT- ED hCG IN POSTMENOPAUSAL WOMEN}

The USA hCG Reference Service provides a consulting service, maintains a database of cases of elevated $\mathrm{hCG}$, and has presented a protocol for evaluating hCG elevations measured using commercial assays in postmenopausal women (Figure 1).2,23

The first step is to confirm hCG elevations and to exclude false-positive readings due to interfering heterophilic antibodies by repeating the measurement using different commercial assays. If the results differ by less than $10 \%$, then interference can be excluded.

The next step is to exclude nontrophoblastic malignancy by measuring the free beta subunit and calculating the free beta subunit immunoreactivity (by multiplying the free beta subunit value by 17). If the calculated free beta subunit immunoreactivity is $30 \%$ or less, then malignancy is unlikely.

The last step is to confirm the pituitary gland as the source of hCG by demonstrating hCG suppression after 3 weeks of hormone therapy. High-estrogen birth control pills containing $50 \mu \mathrm{g}$ of ethinyl estradiol plus progesterone are recommend. Hormone therapy can be discontinued after 3 weeks unless medically indicated for other reasons.

Women who cannot undergo hormone suppression can instead be tested using a $\mathrm{GnRH}$ analogue such as leuprolide 3.75 intramuscularly. Despite an initial surge of hCG after GnRH stimulation, the level becomes suppressed within 1 week through desensitization of the pituitary to a continuous $\mathrm{GnRH}$ output, as opposed to the pulsatile GnRH secretion seen in the physiologic state. Levels of hCG of pituitary origin will be suppressed several days after $\mathrm{GnRH}$ analogues are given, whereas hCG secreted from a tumor will not. A pituitary source is confirmed if hCG is suppressed to normal levels 10 days after injection. ${ }^{20,21}$

\section{DISCLOSURES}

The authors report no relevant financial relationships which, in the context of their contributions, could be perceived as a potential conflict of interest.

\section{REFERENCES}

1. Nwabuobi C, Arlier S, Schatz F, Guzeloglu-Kayisli O, Lockwood CJ, Kayisli UA. hCG: biological functions and clinical applications. Int J Mol Sci 2017; 18(10):2037. doi:10.3390/ijms18102037

2. Cole LA, Khanlian SA, Muller CY. Detection of perimenopause or postmenopause human chorionic gonadotropin: an unnecessary source of alarm. Am J Obstet Gynecol 2008; 198(3):275.e1-7. doi:10.1016/j.ajog.2007.09.034

3. Cole LA, Sasaki Y, Muller CY. Normal production of human chorionic gonadotropin in menopause. N Engl J Med 2007; 356(11):11841186. doi:10.1056/NEJMc066500

4. Snyder JA, Haymond S, Parvin CA, Gronowski AM, Grenache DG. Diagnostic considerations in the measurement of human chorionic gonadotropin in aging women. Clin Chem 2005; 51(10):1830-1835. doi:10.1373/clinchem.2005.053595
5. Cole LA. New discoveries on the biology and detection of human chorionic gonadotropin. Reprod Biol Endocrinol 2009; 7:8. doi:10.1186/1477-7827-7-8

6. Cole LA. Biological functions of hCG and hCG-related molecules. Reprod Biol Endocrinol 2010; 8:102. doi:10.1186/1477-7827-8-102

7. Thomas CM, Reijnders FJ, Segers MF, Doesburg WH, Rolland R. Human choriogonadotropin (hCG): comparisons between determinations of intact hCG, free hCG beta-subunit, and "total" hCG + beta in serum during the first half of high-risk pregnancy. Clin Chem 1990; 36(4):651-655. pmid:1691055

8. Fan C, Goto S, Furuhashi Y, Tomoda Y. Radioimmunoassay of the serum free beta-subunit of human chorionic gonadotropin in trophoblastic disease. J Clin Endocrinol Metab 1987; 64(2):313-318. doi:10.1210/jcem-64-2-313

9. Cole LA. Immunoassay of human chorionic gonadotropin, its free subunits, and metabolites. Clin Chem 1997; 43(12):2233-2243. 


\section{EL HAGE AND HATIPOGLU}

pmid:9439438

10. Patel KK, Gronowski AM. Heterophile antibody interference in qualitative urine/serum hCG devices: case report. Clin Biochem 2016; 49(9):729-731. doi:10.1016/j.clinbiochem.2015.12.018

11. Cole LA, Rinne KM, Shahabi S, Omrani A. False-positive hCG assay results leading to unnecessary surgery and chemotherapy and needless occurrences of diabetes and coma. Clin Chem 1999; 45(2): 313-314. pmid:9931066

12. Cole LA. "Background" human chorionic gonadotropin in healthy, nonpregnant women. Clin Chem 2005; 51(10):1765-1766. doi:10.1373/clinchem.2005.056507

13. Cole LA, Khanlian SA. Inappropriate management of women with persistent low hCG results. J Reprod Med 2004; 49(6):423-432. pmid: 15283048

14. Gronowski AM, Fantz CR, Parvin CA, et al. Use of serum FSH to identify perimenopausal women with pituitary hCG. Clin Chem 2008; 54(4):652-656. doi:10.1373/clinchem.2007.100305

15. Patel KK, Qavi AJ, Hock KG, Gronowski AM. Establishing reference intervals for hCG in postmenopausal women. Clin Biochem 2017; 50(4-5):234-237. doi:10.1016/j.clinbiochem.2016.11.017

16. Stenman UH, Alfthan H, Ranta T, Vartiainen E, Jalkanen J, Seppälä M. Serum levels of human chorionic gonadotropin in nonpregnant women and men are modulated by gonadotropin-releasing hormone and sex steroids. J Clin Endocrinol Metab 1987; 64(4):730-736. doi:10.1210/jcem-64-4-730

17. Pekonen F, Alfthan H, Stenman UH, Ylikorkala O. Human chorionic gonadotropin (hCG) and thyroid function in early human pregnancy: circadian variation and evidence for intrinsic thyrotropic activity of hCG. J Clin Endocrinol Metab 1988; 66(4):853-856. doi:10.1210/jcem-66-4-853

18. Matsuura S, Ohashi M, Chen HC, et al. Physicochemical and immunological characterization of an HCG-like substance from human pituitary glands. Nature 1980; 286(5774):740-741. doi:10.1038/286740a0

19. Chen HC, Hodgen GD, Matsuura S, et al. Evidence for a gonadotropin from nonpregnant subjects that has physical, immunological, and biological similarities to human chorionic gonadotropin. Proc Natl Acad Sci USA 1976; 73(8):2885-2889. doi:10.1073/pnas.73.8.2885

20. Daiter E, Braunstein GD, Snyder PJ, et al. Gonadotropin-releasing hormone-dependent chorionic gonadotropin secretion in a menopausal woman. J Clin Endocrinol Metab 1994; 78(6):1293-1297. doi:10.1210/jcem.78.6.8200928

21. Santen R, Hasan F, Thoren K, Farooki A. Pituitary as a source of HCG: residual levels after bilateral testicular tumor removal. J Investig Med High Impact Case Rep 2019; 7:2324709619841414. doi:10.1177/2324709619841414

22. Arrieta O, Ortega RMM, Angeles-Sánchez J, et al. Serum human chorionic gonadotropin is associated with angiogenesis in germ cell testicular tumors. J Exp Clin Cancer Res 2009; 28(1):120. doi:10.1186/1756-9966-28-120

23. Cole LA, Laidler LL, Muller CY. USA hCG Reference Service, 10-year report. Clin Biochem 2010; 43(12):1013-1022. doi:10.1016/j.clinbiochem.2010.05.006

Address: Betul Hatipoglu, MD, University Hospitals of Cleveland, CMC Mather Suite 16000, 11100 Euclid Avenue, Cleveland, OH 44106; betul.hatipoglu@uhhospitals.org 